\title{
Deslocamento miscível de um efluente de indústria de explosivo em colunas de solo
}

\author{
William Vilar Garcia ('); Marco Aurélio Kondracki de Alcântara (1*); Otávio Antonio de Camargo (²); \\ Hélcio José Izário Filho ('); Fernando Dini Andreote ( $\left.{ }^{3}\right)$ \\ (1) Universidade de São Paulo, Escola de Engenharia de Lorena, Caixa Postal 116, 12602-810 Lorena (SP), Brasil. \\ (2) Institudo Agronômico, Centro de Pesquisa e Desenvolvimento em Solos e Recursos Agroambientais, Caixa Postal 28, 13020-902 \\ Campinas (SP), Brasil. \\ (3) Universidade de São Paulo, Escola Superior de Agricultura “Luiz de Queiroz”, Caixa Postal 9, 13418-900 Piracicaba (SP), Brasil. \\ $\left({ }^{*}\right)$ Autor correspondente: marko@usp.br
}

Recebido: 6/abr./2011; Aceito:15/nov./2011

\section{Resumo}

Este estudo teve como objetivo avaliar alguns impactos decorrentes do deslocamento miscível de efluente de nitração de uma indústria de explosivos aplicado em colunas de um Latossolo Amarelo, horizonte B (LA-B), submetido aos tratamentos: adição de carbonatos (BASE), ácidos (ACID), fosfato (FOSF), carbonatos e fosfato (BASE-FOSF) e ácidos e fosfatos (ACID-FOSF). A recuperação de nitrogênio em relação ao total aplicado varia entre 10,1 (ACID) e 65,5\% (BASE). Há correlação significativa entre as curvas de transposição de $\mathrm{N}$ obtidas experimentalmente e as simuladas pelo aplicativo STANMOD para a maioria das colunas $(p<0,001)$. A exceção ocorreu para ACID-FOSF $(p=0,202)$. Não há correlação entre carga eletrostática líquida (CEL) e as variáveis de ajuste do modelo: fator de retardamento (FR), coeficiente de dispersão-difusão (D) e taxa de decaimento de primeira ordem ( $\mu$ ). A adição de fosfato (FOSF) favorece a movimentação do nitrogênio, pois diminui $F R(2,35 \pm 0,05)$ e $\mu\left(0,498 \pm 0,050 \mathrm{~h}^{-1}\right)$ e aumenta $D\left(41,8 \pm 5,5 \mathrm{~cm}^{2} \mathrm{~h}^{-1}\right)$ em relação ao observado na coluna $L A-B\left(2,51 \pm 0,03 ; 1,697 \pm 0,084 \mathrm{~h}^{-1}\right.$ e $2,8 \pm 1,3 \mathrm{~cm}^{2} \mathrm{~h}^{-1}$ respectivamente). A adição de carbonatos e/ou fosfatos (BASE, BASE/FOSF e FOSF) resultou nos maiores valores máximos de demanda química de oxigênio $\left(\mathrm{DQO}_{\mathrm{MAX}}\right.$ ). A pequena quantidade de DNA extraída das células bacterianas nos solos sugere que, possivelmente, os processos que governam a adsorção e movimentação de $\mathrm{N}$ sejam de natureza não biológica ou que a elevada DQO do líquido percolado prejudica os microrganismos do solo.

Palavras-chave: deslocamento miscível, nitrogênio, curvas de transposição, PCR-DGGE.

\section{Miscible displacement of an explosive industry effluent on soil columns}

\begin{abstract}
This study evaluated some impacts due to the miscible displacement of an explosive industry effluent applied to a B horizon of an Udox soil (LA-B) under the following treatments: additions of carbonate (BASE), acid (ACID), phosphate (FOSF), carbonate and phosphate (BASE-FOSF) and acid and phosphate (ACID-FOSF). Nitrogen recovery compared with the total amount applied varies from 10.1\% (ACID) to 65.5\% (BASE). There is correlation between experimental and fitted breakthrough curves for the most columns ( $p<0.001)$. The unique exception occurs to ACID-FOSF $(p=0.202)$. There is no correlation between soil net electrostatic charge (NEC) and the model adjusted variables: retardation factor (FR), dispersion-diffusion coefficient (D) and first-order decaying rate $(\mu)$. Phosphate adding (FOSF) favors nitrogen movement, since reduces FR $(2.35 \pm 0.05)$ and $\mu\left(0.498 \pm 0.050 \mathrm{~h}^{-1}\right)$ and increases $\mathrm{D}\left(41.8 \pm 5.5 \mathrm{~cm}^{2} \mathrm{~h}^{-1}\right)$, compared to LA-B column $(2.51 \pm 0.03$; $1.697 \pm 0.084 \mathrm{~h}^{-1}$ and $2.85 \pm 1.26 \mathrm{~cm}^{2} \mathrm{~h}^{-1}$, respectively). Adding carbonate and/or phosphate (BASE, BASE/FOSF e FOSF) results in the highest values for maximum chemical oxygen demand $\left(\mathrm{COD}_{\text {MAx }}\right)$. The small DNA amount extracted from soil bacterial cells suggests that the $\mathrm{N}$ adsorption and movement have non biological nature, or that the high leachate liquid COD is prejudicial to soil microorganisms.
\end{abstract}

Key words: miscible displacement, nitrogen, breaktrough curves, PCR-DGGE. 


\section{INTRODUÇÃO}

Por ocasião da utilização de efluentes com fins agrícolas, uma preocupação ambiental refere-se aos impactos decorrentes do seu deslocamento pelos horizontes do solo. Ao se deslocar para regiōes além da zona radicular, o efluente pode causar elevação dos teores de $\mathrm{N}$ e da demanda química de oxigênio (DQO) nos aquíferos subterrâneos e diversos efeitos sobre a microfauna do solo. Os teores recuperados de vários elementos no líquido percolado através de colunas de solo têm sido utilizados em alguns trabalhos para quantificar sua movimentação (AlcÂNTARA e CAMARgo, 2004; BARIzon et al., 2006). A simulação do movimento de solutos tem sido feita de maneira simplificada, considerando o fluxo saturado. Embora no campo as condiçōes reais de fluxo sejam geralmente não saturadas, essa simplificação tem sido utilizada por não implicar erros significativos em estimativas de curto prazo (Nielsen et al., 1986). Teoricamente, a manutenção de um fluxo saturado resultaria em uma abordagem mais conservadora em relação ao movimento de solutos. Essa abordagem conservadora foi utilizada para estudar a adsorção dinâmica de amônio em colunas de solo sob condiçóes de fluxo saturado por JELLALI et al. (2010), bem como a movimentação de nitrato em colunas de solo (AlCÂNTARA e CAMARgo, 2010a,b).

Mais recentemente, a movimentaçáo tem sido estudada utilizando-se modelos físico-matemáticos (AlcÂNTARA e Camargo, 2010a,b; Jellali et al., 2010; Zhang et al., 2009). Tais modelos são resultantes de soluçôes da equação diferencial de transporte de solutos no solo, com base no fluxo de massa, dispersão, difusão e retardamento dos solutos em relação ao avanço da interface entre o líquido deslocador e o deslocado. Em algumas situaçóes, assumese também que tanto o soluto na fase aquosa como o adsorvido no solo estão sujeitos a reaçóes de decaimento, governadas por reaçóes cinéticas de primeira ordem. A equação que governa uma reação de decaimento desse tipo pode ser representada por (Zheng e BenNetT, 2004):

$\frac{\partial C}{\partial t}=-\mu \times C$

em que $C$ é a concentração do soluto, $t$ é o tempo de reaçáo e $\mu$ é a constante (ou taxa) de decaimento de primeira ordem. Evidentemente, a solução da equação (1), resulta em uma equação cinética de primeira ordem (Equação 2):

$C(t)=C_{0} \times e^{-\mu \times t}$

Reaçôes desse tipo podem envolver, entre outras, decaimento radioativo, hidrólise, e algumas formas de biodegradação (Zheng e Bennett, 2004). AlcÂntara et al. (2007), por exemplo, utilizaram com sucesso a equação (2) para descrever a mineralização do $\mathrm{N}$ orgânico existente em lodo de curtume.
Programas computacionais aplicados a dados experimentais oriundos de ensaios de deslocamento miscível em colunas constituem-se em ferramentas para o estudo da dinâmica de solutos no solo. Existem diversos aplicativos computacionais, como o STANMOD (SIMUNEK et al., 2008), por exemplo. Esse aplicativo, além de verificar o ajuste entre os dados experimentais e os simulados, fornece três importantes variáveis de transporte: o fator de retardamento (FR), o coeficiente de dispersão-difusão (D) e a taxa de decaimento de primeira ordem $(\mu)$.

A DQO é um índice importante na avaliação de impactos causados ao ambiente pela adição de efluentes, indicando a quantidade de oxigênio que seria consumida pelas reaçóes químicas de oxidação de diversos compostos orgânicos presentes.

Estimar a diversidade microbiana do solo é outro aspecto a ser considerado. Muitas abordagens são possíveis na estimativa dessa população. O PCR-DGGE separa amplicons de PCR de tamanhos similares baseada na diferença de composição de sequências em um gel com gradiente de desnaturação, e tem sido utilizado para estudar comunidades microbianas em ambientes distintos (ANDreote et al., 2009).

Este trabalho objetivou avaliar alguns impactos decorrentes do deslocamento miscível de um efluente de uma indústria de explosivos aplicado em colunas de solos. Especificamente, avaliaram-se: (a) a movimentaçáo do nitrogênio proveniente desse efluente pelo solo; (b) os impactos na DQO decorrentes da movimentaçấo e (c) a possível participação da diversidade microbiana do solo nessa movimentação, ainda que de modo exploratório.

\section{MATERIAL E MÉTODOS}

Foi utilizada uma amostra deformada do horizonte B de um Latossolo Amarelo (EMBrapa, 2006), coletada na cidade de Lorena, Estado de São Paulo, Brasil (Coordenadas UTM: 7.490.171 m N, $488.507 \mathrm{~m} \mathrm{E).} \mathrm{O} \mathrm{solo} \mathrm{foi} \mathrm{coleta-}$ do na profundidade de 50 a $120 \mathrm{~cm}$, secado ao ar e tamisado a $2 \mathrm{~mm}$. Os atributos químicos e físicos do solo original eram: $\mathrm{pH}, 4,1$; matéria orgânica, $26,0 \mathrm{~g} \mathrm{dm}^{-3}$ solo; $\mathrm{P}, 7,0 \mathrm{mg} \mathrm{dm}^{-3} ; \mathrm{K}, 1,3 \mathrm{mmol} \mathrm{dm}^{-3}$; $\mathrm{Ca}, 11,0 \mathrm{mmol} \mathrm{dm}^{-3}$; $\mathrm{Mg}, 4,0 \mathrm{mmol} \mathrm{dm}_{\mathrm{c}}^{-3} ; \mathrm{Al}_{+} \mathrm{H}, 56,0 \mathrm{mmol} \mathrm{dm}_{\mathrm{c}}^{-3}$; CTC, $72,0 \mathrm{mmol}_{\mathrm{c}} \mathrm{dm}^{-3}$; argila, $325 \mathrm{~g} \mathrm{~kg}^{-1}$; Fe: $171 \mathrm{mg} \mathrm{dm}^{-3} \mathrm{e}$ areia $569,9 \mathrm{~g} \mathrm{~kg}^{-1}$. Todos esses atributos foram determinados ou estimados de acordo com CAmargo et al. (2009) e RaIj et al. (2001).

O efluente utilizado foi gerado na etapa de nitraçáo por uma indústria de materiais explosivos situada no município de Piquete, Estado de São Paulo, Brasil. O pH desse efluente é muito baixo $(0,9)$, o que o torna inadequado para disposição direta no ambiente. De acordo com as normas do Conselho Nacional do Meio Ambiente (BrasiL, 2005), para que um efluente possa ser lançado em corpos 
de água, o seu $\mathrm{pH}$ deve estar situado entre 5 e 9. Assim, o $\mathrm{pH}$ do efluente foi previamente corrigido para 6,5 com hidróxido de potássio. Por outro lado, no efluente há um teor relativamente alto de $\mathrm{N}\left(1,35 \mathrm{~g} \mathrm{~L}^{-1}\right)$. Outro dado positivo para utilização agrícola desse efluente refere-se às baixas concentraçóes de metais pesados, todos abaixo dos valores de intervenção estipulados pela CETESB (2005). A DQO obtida no efluente é $86 \mathrm{mg} \mathrm{O}_{2} \mathrm{~L}^{-1}$, próximo do limite máximo para lançamento direto em corpos de água, o qual é de $90 \mathrm{mg} \mathrm{O}_{2} \mathrm{~L}^{-1}$ (Sperling, 1996).

Amostras do solo utilizado foram submetidas a diferentes manejos químicos, visando simular (de maneira intensificada) situações práticas que ocorrem em solos agrícolas. Foram aplicados os seguintes tratamentos aos solos: (1) LA-B: solo em condiçōes "naturais", ou seja, sem adição de corretivos ou fertilizantes; (2) ACID: submetido a lixiviação prévia com ácido clorídrico de modo a fornecer $4 \mathrm{~mol} \mathrm{H}^{+} \mathrm{kg}^{-1}$ solo, seguido de remoção do excesso de íons $\mathrm{H}^{+}$por percolaçáo do solo com água destilada; (3) BASE: solo incubado previamente durante três meses com hidroxicarbonato de magnésio, $5,2 \mathrm{~g} \mathrm{~kg}^{-1}$ solo; (4) FOSF: incubação do por três meses com di-hidrógeno fosfato monobásico, $400 \mathrm{mg} \mathrm{P} \mathrm{kg}^{-1}$ solo; (5) ACID-FOSF: adição de ácido e fosfato (combinação dos tratamentos ACID e FOSF) e (6) BASE-FOSF: adição de carbonato e de fosfato (combinaçáo dos tratamentos BASE e FOSF). As determinaçóes das cargas eletrostáticas líquidas (CEL) nas amostras após receberem esses tratamentos foram feitas de acordo com CAMARGO et al. (2009).

A movimentação do efluente no solo foi investigada em colunas de percolação, tendo em vista a teoria do deslocamento miscível. O método utilizado no manejo das colunas foi adaptado de Alcântara e Camargo (2001). As colunas de percolação tinham $5,6 \mathrm{~cm}$ de diâmetro interno e $30 \mathrm{~cm}$ de altura. Utilizou-se bomba peristáltica para aplicar fluxo constante e saturado, de $8,2 \pm 0,4 \mathrm{~cm} \mathrm{~h}^{-1}$. As colunas foram previamente saturadas vagarosamente a partir da base com $\mathrm{CaCl}_{2} 50 \mathrm{mmol} \mathrm{L}^{-1}$. A coleta das amostras no efluente foi feita a intervalos regulares, utilizandose um coletor automático de frações. Foram construídas curvas de transposiçáo de nitrogênio, obtidas a partir da concentração relativa $\mathrm{C} / \mathrm{C}_{0}$ em funçáo do volume de po$\operatorname{ros} V / \mathrm{V}_{0}$ aplicado $\left(\mathrm{C}_{0}\right.$ é a concentraçáo inicial do elemento no pulso de efluente e $\mathrm{V}_{0}$ é o volume ocupado pelos poros na coluna). Considerando-se uma porosidade do solo igual a $0,387 \mathrm{~cm}^{3} \mathrm{~cm}^{-3}, V_{0}$ foi de $0,286 \mathrm{~L}$. Os teores de nitrogênio no solo, no efluente $\left(\mathrm{C}_{0}\right)$ e no líquido recuperado (C) após percolaçáo pela coluna, foram determinados por arraste a vapor (método de Kjeldhal), conforme RAIJ et al. (2001), em duas repetiçóes por amostra coletada. Para cada solo foi conduzida uma coluna, sem emprego de repetiçáo. Dada a natureza experimental complexa do deslocamento miscível, esse procedimento tem sido utilizado quando o interesse for avaliar qualitativamente a tendência do fenômeno (Zhang et al., 2009; ZhaO et al., 2009; Jellali et al., 2010).
Foi feito o balanço do nitrogênio e aplicou-se um modelo matemático para estudo da movimentação. $\mathrm{O}$ balanço do nitrogênio foi calculado considerando-se a porcentagem de recuperação de nitrogênio (\%-RECUPERADA), de acordo com a equação (3):

$$
\% \text { - RECUPERADA }=\frac{\mathrm{N}-\mathrm{RECUPERADO}}{\mathrm{N}-\text { APLICADO }} \times 100
$$

O N-APLICADO foi obtido multiplicando-se a $\mathrm{C}_{0}$ pelo volume aplicado de pulso $(100 \mathrm{~mL})$. A quantidade total de nitrogênio recuperada (N-RECUPERADO) foi calculada, então, como a área sob a curva do gráfico de concentração de nitrogênio $(\mathrm{C})$, em função do volume total aplicado de pulso mais soluçáo deslocadora (V). Essa área foi calculada pela Regra Trapezoidal, utilizando-se o aplicativo computacional QtiPlot versão 0.9.8.2 (para ambiente Linux). As quantidades recuperadas (N-RECUPERADO) em cada tratamento foram correlacionadas com as respectivas CEL, obtendo-se o coeficiente de correlação (R). A significância do F dessa análise (p) foi calculada utilizando-se o aplicativo computacional Gnumeric v.1.10.13 (para ambiente Linux).

Para simular a movimentação do N pelo solo, foi utilizado o aplicativo computacional STANMOD, versão 2.07 (2003). Uma descrição sucinta das equações e pressuposiçóes teóricas do modelo utilizado encontra-se em Alcântara e Camargo (2010a). Na utilização do aplicativo, são pedidas diversas variáveis de entrada, determinados experimentalmente: comprimento da coluna $(Z)$; velocidade (fluxo) do líquido nos poros $(v)$, obtido dividindo-se o fluxo de Darcy aplicado $\left(\mathrm{q}=11,12 \mathrm{~cm} \mathrm{~h}^{-1}\right)$ pela porosidade do solo $\left(0,387 \mathrm{~cm}^{3} \mathrm{~cm}^{-3}\right)$; umidade volumétrica $(\theta)$, considerada igual à porosidade do solo, uma vez que o fluxo foi mantido saturado; concentração inicial do pulso $\left(\mathrm{C}_{0}\right)$; duraçáo da aplicaçáa do pulso $\left(\mathrm{t}_{\mathrm{p}}\right)$; intervalo de coleta de cada amostra no efluente $(\Delta t)$ e número de amostras que farão parte do ajuste $(\mathrm{N})$. O STANMOD utiliza o módulo CXTFIT atualizado (Toride et al., 1995), para otimizar variáveis de transporte pelo método dos mínimos quadrados. As variáveis aqui ajustadas automaticamente foram o coeficiente de retardamento (FR), o coeficiente de dispersão-difusão (D) e a taxa de decaimento de primeira ordem $(\mu)$. A adequaçáo do modelo para descrever a movimentaçáo foi avaliada calculando-se a significância do $\mathrm{F}$ da análise de correlação (p), utilizando-se novamente o aplicativo computacional Gnumeric v.1.10.13 (para ambiente Linux).

Nas amostras de lixiviado coletadas foi determinada a DQO de acordo com APHA (1992). A partir dessas determinaçôes, foram construídas curvas de DQO, de modo semelhante às curvas de nitrogênio. As curvas de transposição de $\mathrm{DQO}$ foram analisadas considerando-se os valores máximos de $\mathrm{DQO}$ obtidos $\left(\mathrm{DQO}_{\mathrm{MÁX}}\right)$. A análise da diversidade microbiana nos solos das colunas foi feita utilizando a técnica de PCR-DGGE (Muyzer e Smalla, 1998). 


\section{RESULTADOS E DISCUSSÃO}

A CEL dos solos para os diferentes tratamentos variou entre $-2,5$ e $+27,3 \mathrm{mmol}_{\mathrm{c}} \mathrm{kg}^{-1}$ solo. Nas colunas BASE e BASE-FOSF ocorreram as maiores reduçôes nos valores algébricos da CEL, que passou de $-2,5 \mathrm{mmol}_{\mathrm{c}} \mathrm{kg}^{-1}$ no LA-B para $-14,8$ no BASE e $-18,0$ mmol $_{c} \mathrm{~kg}^{-1}$ e no BASEFOSF. Na coluna FOSF também houve redução do valor algébrico da CEL, que passou de -2,5 (no LA-B) para -7,0 mmol $\mathrm{kg}^{-1}$. Na coluna ACID, houve aumento no valor algébrico da CEL, que passou de -2,5 (no LA-B) para $+27,3 \mathrm{mmol}_{\mathrm{c}} \mathrm{kg}^{-1}$. Tais resultados são semelhantes aos obtidos por AlCÂNTARa e CAMARgo (2005), estudando a adsorção de nitrato em um Latossolo Vermelho acriférrico. Esses Latossolos Vermelhos utilizados são solos com teores elevados de óxidos de ferro, com características anfóteras, nos quais se esperam efeitos acentuados do $\mathrm{pH}$ e de outros fatores sobre as cargas líquidas, como os aqui obtidos.

$\mathrm{Na}$ coluna ACID, que proporcionou maior valor algébrico da CEL $\left(27,3 \mathrm{mmol}_{\mathrm{c}} \mathrm{kg}^{-1}\right)$ entre todos os tratamentos (Tabela 1), foi observado a menor recuperação de $\mathrm{N}(10,1 \%)$. No outro extremo, a maior recuperação de $\mathrm{N}$ foi obtida para a coluna BASE $(65,5 \%)$, que, no entanto, não apresentou o menor valor algébrico (mais negativo) para a CEL.

De fato, não foi observada correlação significativa entre as quantidades recuperadas de $\mathrm{N}$ e as cargas eletrostáticas líquidas $(R=0,463 ; p=0,354)$. Esse resultado é importante do ponto de vista prático, indicando que manejos de solo que

Tabela 1. Balanço de massa de N nas colunas do Latossolo Amarelo submetido aos tratamentos

\begin{tabular}{lccc} 
Coluna & $\begin{array}{c}\text { N-Aplicado } \\
(\mathbf{g})\end{array}$ & $\begin{array}{c}\mathbf{N} \text {-Recuperado } \\
(\mathbf{g})\end{array}$ & $\begin{array}{c}\text { \%-Recuperada (') } \\
\text { (\%) }\end{array}$ \\
\hline LA-B & 0,127 & 0,055 & 43,3 \\
\hline ACID & 0,179 & 0,018 & 10,1 \\
\hline BASE & 0,168 & 0,110 & 65,5 \\
\hline FOSF & 0,171 & 0,084 & 49,1 \\
\hline ACID-FOSF & 0,160 & 0,044 & 27,5 \\
\hline BASE-FOSF & 0,174 & 0,052 & 29,9
\end{tabular}

('): \%-Recuperada $=(\mathrm{N}-$ Recuperado/N-Aplicado $) \times 100$. promovam o surgimento de cargas positivas no solo não seriam necessariamente eficientes na diminuiçáo da recuperação do elemento. Porém, quando a coluna BASE-FOSF é exlcuída dessa correlação, o grau de associação entre CEL e as quantidades recuperadas melhora muito, embora ainda não seja significativo a $5 \%(\mathrm{R}=0,859 ; \mathrm{p}=0,062)$. A falta de repetiçōes não possibilita afirmar com certeza se isso é reflexo de um mecanismo de transporte realmente diferenciado nessa coluna ou foi influenciado por fatores ligados ao erro experimental. Embora AlcÂNTARA e Camargo (2005) e Donn e Menzies (2005a,b) tenham verificado que as cargas positivas do solo adsorvam o nitrato, não significa que a quantidade total lixiviada seja inversamente proporcional a essa adsorção. Assim, o que pode ter ocorrido neste trabalho é o retardamento da movimentação desse íon em relação ao avanço da água pelo solo. Em teoria, parte do nitrogênio lixiviado poderia ser proveniente da mineralização da matéria orgânica do solo. Porém, há que se considerar que as colunas foram lixiviadas por curto período de tempo, o que não deve ter possibilitado a mineralização de quantidades apreciáveis desse elemento. Cabe lembrar que, antes do início das amostras do líquido na base da coluna, estas foram intensamente lixiviadas para regularização do fluxo, o que levou a remoção do $\mathrm{N}$ previamente existente. Quando se lixiviam íons fortemente adsorvidos pelo solo, a relação entre cargas eletrostáticas e quantidade total recuperada parece ser mais evidente, como constatado por Alcântara e Camargo (2001), estudando a movimentação de cromo em colunas de solo. De qualquer maneira, tal associação entre CEL e recuperação de nitrogênio merece ser explorada em trabalhos futuros, uma vez que os resultados da literatura são divergentes nessa questão.

A correlação entre os dados obtidos experimentalmente e aqueles simulados pelo modelo para as curvas de transposição (utilizando as variáveis de entrada apresentadas na Tabela 2) variou de $0,184(\mathrm{p}=0,202)$ a 0,977 $(\mathrm{p}<0,001)$ (Tabela 3). Ou seja, para a maioria das colunas houve associação significativa (a $0,1 \%)$ entre os valores obtidos experimentalmente e aqueles simulados pelo modelo. Tais resultados indicam que o modelo conseguiu descrever a movimentaçáo de nitrogênio na maioria das

Tabela 2. Variáveis de entrada para o modelo obtidas para o Latossolo Amarelo submetido aos diferentes tratamentos

\begin{tabular}{|c|c|c|c|c|c|c|c|}
\hline \multirow{3}{*}{ Colunas } & \multicolumn{7}{|c|}{ Variáveis } \\
\hline & $x$ & $\theta$ & $v$ & $C_{0}$ & $t_{p}$ & $\Delta \mathrm{t}$ & Número \\
\hline & $(\mathrm{cm})$ & $\left(\mathrm{cm}^{3} \mathrm{~cm}^{-3}\right)$ & $\left(\mathrm{cm} \mathrm{h}^{-1}\right)$ & $\left(\mathrm{g} \mathrm{L}^{-1}\right)$ & (h) & (h) & \\
\hline LA-B & 30 & 0,3870 & 28,74 & 1,31 & 0,66 & 0,1250 & 37 \\
\hline ACID & 30 & 0,3870 & 28,74 & 1,68 & 0,66 & 0,1250 & 27 \\
\hline BASE & 30 & 0,3870 & 28,74 & 1,68 & 0,66 & 0,1667 & 44 \\
\hline FOSF & 30 & 0,3870 & 28,74 & 1,71 & 0,66 & 0,1202 & 27 \\
\hline ACID-FOSF & 30 & 0,3870 & 28,74 & 1,60 & 0,66 & 0,1250 & 28 \\
\hline BASE-FOSF & 30 & 0,3870 & 28,74 & 1,74 & 0,66 & 0,1238 & 30 \\
\hline
\end{tabular}

$\mathrm{x}$ : comprimento da coluna; $\theta$ : umidade volumétrica, considerado igual a porosidade do solo; $v$ : fluxo de água nos poros, obtido dividindo-se o fluxo de Darcy pela porosidade do solo; $\mathrm{C}_{0}$ : concentraçấo inicial de nitrogênio no pulso de efluente; $\mathrm{t}_{\mathrm{p}}$ : tempo de aplicação do pulso; $\Delta \mathrm{t}$, tempo de coleta em cada tubo; Número de tubos coletados até completar a curva de transposiçáo. O número de tubos correspondeu ao número de amostras coletadas desde o início da aplicaçấo do pulso até o momento em que a curva de transposiçâo atingia novamente concentraçôes mínimas, próximas a zero. 
colunas de solo. A única exceção ocorreu para a coluna ACID-FOSF $(R=0,184, p=0,202)$. A falta de correlação significativa nessa coluna é um resultado interessante, e que merece ser investigada em estudos futuros.

Esses ajustes podem ser percebidos visualmente quando se comparam as curvas de transposição obtidas experimentalmente com aquelas simuladas pelo modelo (Figura 1).

Os ajustes obtidos neste estudo foram melhores do que os obtidos por Alcântara e Camargo (2010b), que estudando a movimentaçáo de nitrato em colunas de solo, encontraram $R$ variando entre $0,484(p=0,482)$ e 0,977 $(\mathrm{p}=0,072)$. Aqueles autores observaram boa coincidência visual entre as curvas obtidas experimentalmente e as ajustadas pelo modelo somente em algumas colunas.

A variável FR pode ser entendida como uma medida da defasagem entre o avanço do líquido e do soluto pela coluna. Assim, seria esperado que, à medida que a CEL aumentasse algebricamente, o FR também aumentasse, já que a adsorção do nitrato é essencialmente eletrostática. No entanto, não foi observado correlação entre CEL e FR ( $R=0,003, p=0,996)$. Logicamente, não foi incluída nessa correlação a ACID-FOSF, uma vez que o modelo não conseguiu descrever a movimentação de $\mathrm{N}$ nessa coluna. Nas colunas que receberam adição de fosfato, ou seja, FOSF e BASE-FOSF, os FR foram $2,35 \pm 0,05$ e $2,48 \pm 0,03$, menores do que para a LA-B $(2,51 \pm 0,03)$. Valores menores de FR, representam, em termos práticos, antecipação do avanço do nitrogênio pelo perfil do solo. QAFOKU e Sumner (2001) verificaram diminuição no FR com a adição de carbonatos no solo. Porém, isso náo foi observado por Alcântara e Camargo (2010a,b), estudando a movimentação de uma solução salina de nitrato. Tais resultados contrastantes sugerem que essa questão ainda necessita de mais estudos.

Tabela 3. Coeficientes de correlação $(\mathrm{R})$ e respectivas significâncias da análise de regressão (p) entre os dados experimentais e ajustados; fatores de retardamento (FR); e coeficientes de dispersão-difusão (D) e taxas de decaimento ( $\mu$ ) fornecidos pela aplicação do modelo ao solo Latossolo Amarelo submetido aos diferentes tratamentos, após a condução das colunas

\begin{tabular}{lccccc} 
Coluna & $\mathbf{R}$ & $\mathbf{p}$ & $\mathbf{F R}$ (adimensional) & $\mathbf{D}\left(\mathbf{c m}^{\mathbf{2}} \mathbf{h}^{-1}\right)$ & $\boldsymbol{\mu}\left(\mathbf{h}^{-1}\right)$ \\
LA-B & 0,954 & $<0,001$ & $2,513 \pm 0,033$ & $2,849 \pm 1,261$ & $1,697 \pm 0,084$ \\
ACID & 0,912 & $<0,001$ & $2,505 \pm 0,028$ & $2,400 \pm 0,901$ & $1,959 \pm 0,070$ \\
BASE & 0,955 & $<0,001$ & $2,597 \pm 0,048$ & $31,74 \pm 4,204$ & $0,2695 \pm 0,051$ \\
FOSF & 0,940 & $<0,001$ & $2,348 \pm 0,052$ & $41,77 \pm 5,519$ & $0,4983 \pm 0,050$ \\
\hline ACID-FOSF & 0,184 & 0,202 & Não ajustado & Não ajustado & Não ajustado \\
BASE-FOSF & 0,979 & $<0,001$ & $2,476 \pm 0,026$ & $2,422 \pm 0,928$ & $2,002 \pm 0,070$
\end{tabular}

R: coeficiente de correlaçáo; p: probabilidade de obterem-se resultados fora da regiấo de conclusão pela análise de variância da regressão (se p $<0,001$ a correlaçáo entre os dados experimentais e simulados é significativa a $0,1 \%$ ); FR: fator de retardamento; D: coeficiente de difusão-dispersão e $\mu$ : taxa de decaimento. Năo ajustado, indica que o valor fornecido pelo aplicativo computacional não é confiável, uma vez que o R nấo foi significativo a $5 \%$.

(a)

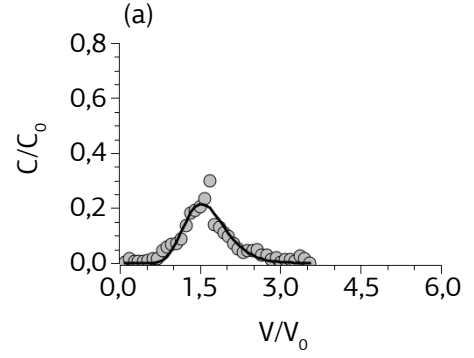

(b)

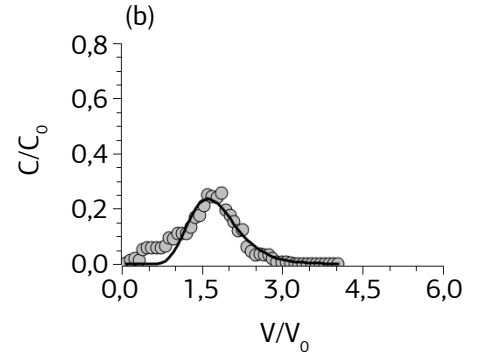

(c)

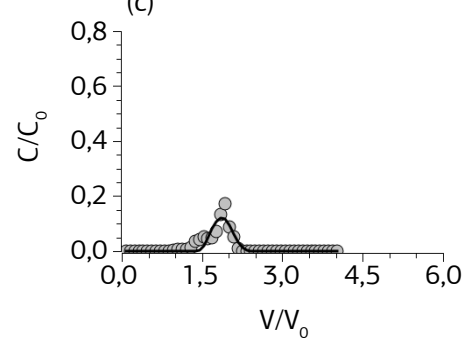

(d)

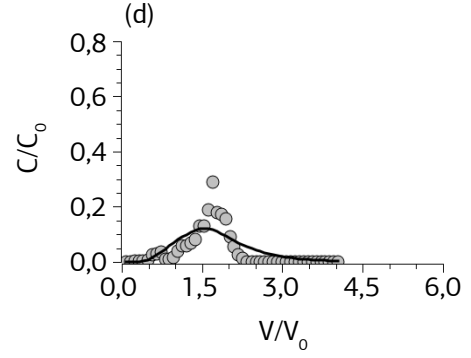

(e)
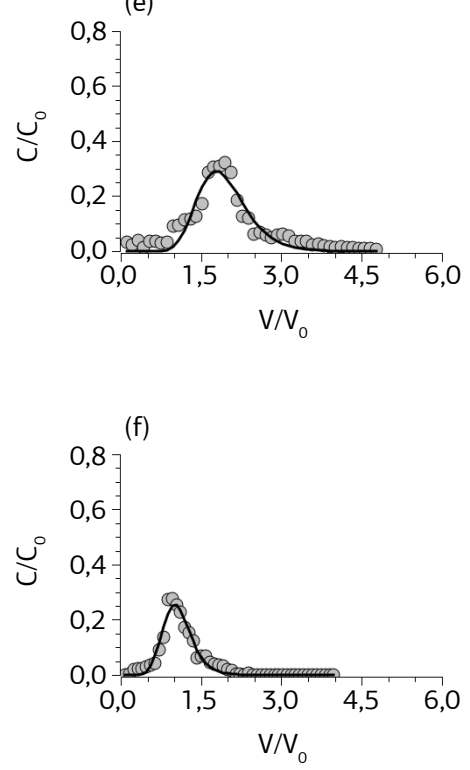

Figura 1. Curvas de transposiçáo de nitrogênio para os dados obtidos experimentalmente e os dados ajustados pelo modelo: (a) LA-B; (b) FOSF; (c) ACID; (d) ACID-FOSF; (e) BASE e (f) BASE-FOSF. Os pontos correspondem aos dados obtidos experimentalmente e a linha contínua ao ajuste feito pelo modelo (os pontos correspondem à média de duas determinaçóes). $\mathrm{C} / \mathrm{C}_{0}$ : concentração relativa (adimensional); $\mathrm{V} / \mathrm{V}_{0}$ : volume de poros de pulso+soluçáo deslocadora aplicado (adimensional). 
Também não foi verificada correlação entre CEL e D $(\mathrm{R}=0,367, \mathrm{p}=0,544)$. Pelos mesmos motivos expostos anteriormente, também se excluiu dessa correlação a coluna ACID-FOSF. Nas colunas BASE e BASE-FOSF, os D foram respectivamente $31,74 \pm 4,20$ e $41,77 \pm 5,52 \mathrm{~cm}^{2} \mathrm{~h}^{-1}$, significativamente maiores do que na LA-B $\left(2,85 \pm 1,26 \mathrm{~cm}^{2} \mathrm{~h}^{-1}\right)$, indicando que a dispersão-difusão foi facilitada pela incorporação de carbonatos e de fosfatos ao solo.

De modo semelhante ao observado para os outros dois parâmetros do modelo, não houve correlação entre CEL e $\mu(\mathrm{R}=0,416, \mathrm{p}=0,487)$. Nas colunas BASE e BASE-FOSF, os $\mu$ obtidos $\left(0,270 \pm 0,051\right.$ e $2,002 \pm 0,070 \mathrm{~h}^{-1}$, respectivamente) foram significativamente menores em relação à LA-B $\left(1,697 \pm 0,084 \mathrm{~h}^{-1}\right)$.

Em análise conjunta das correlações entre CEL e as diferentes variáveis ajustadas pelo modelo, observa-se que em todas elas a adição combinada de carbonatos e fosfatos (BASE-FOSF) favorece a movimentação de nitrogênio: ao mesmo tempo em que reduz o FR, reduz também o $\mu \mathrm{e}$ aumenta o D. Isso se reveste de importância prática, uma vez que a adição de adubos fosfatados, feita em conjunto com a calagem do solo, é um manejo químico amplamente utilizado na agricultura.

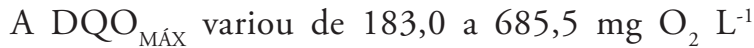
(Figura 2). Esses valores foram significativamente maiores do que a DQO original do efluente $\left(86 \mathrm{mg} \mathrm{O}_{2} \mathrm{~L}^{-1}\right)$. É possível que a presença da solução deslocadora utilizada nas lixiviaçóes tenha contribuído para o aumento da DQO no líquido lixiviado em relação ao valor encontrado no efluente aplicado. Porém, os baixos valores de
DQO encontrados nas extremidades de diversas curvas (quando o efluente aplicado ainda náo havia chegado ao final da coluna ou já havia sido totalmente lixiviado), indicam que esse aumento da DQO não é devido somente à influência da solução deslocadora. O efluente aplicado, ao percorrer a coluna, entra em contato com o solo e seus constituintes. Em consequência, para os diferentes tratamentos aplicados ao solo (adiçấo de diferentes corretivos e fertilizantes), foram obtidas diferentes curvas de DQO, bem como diferentes $\mathrm{DQO}_{\text {MÁX }}$. Os menores teores de $\mathrm{DQO}_{\text {MÁX }}$ foram observados nas curvas obtidas das colunas LA-B, ACID-FOSF e ACID, que não diferiram entre si a $5 \%$ de probabilidade pelo teste de Tukey. Nessas colunas, o baixo pH inicial (igual ou inferior a 4,1), provavelmente favoreceu a predominância de fungos em relação às bactérias, o que talvez pudesse explicar (ao menos parcialmente) os menores valores de DQO. Nas colunas em que o $\mathrm{pH}$ foi elevado (pela adição de carbonatos), pode ter havido favorecimento na população bacteriana em relação à de fungos, com consequente aumento na DQO. Entretanto, esses teores diferiram significativamente e foram crescentes na seguinte ordem: FOSF, BASE-FOSF e BASE. Esse aumento na $\mathrm{DQO}_{\text {MÁX }}$ é preocupante, uma vez que a adição de carbonatos e fosfatos são práticas comumente utilizadas na agricultura. Talvez um tratamento biológico ou químico fosse de extrema importância uma vez que a intenção é aplicar esse efluente rico em nitrogênio como fonte adicional de nutrientes ao solo e às plantas. Cabe lembrar que esses valores podem estar
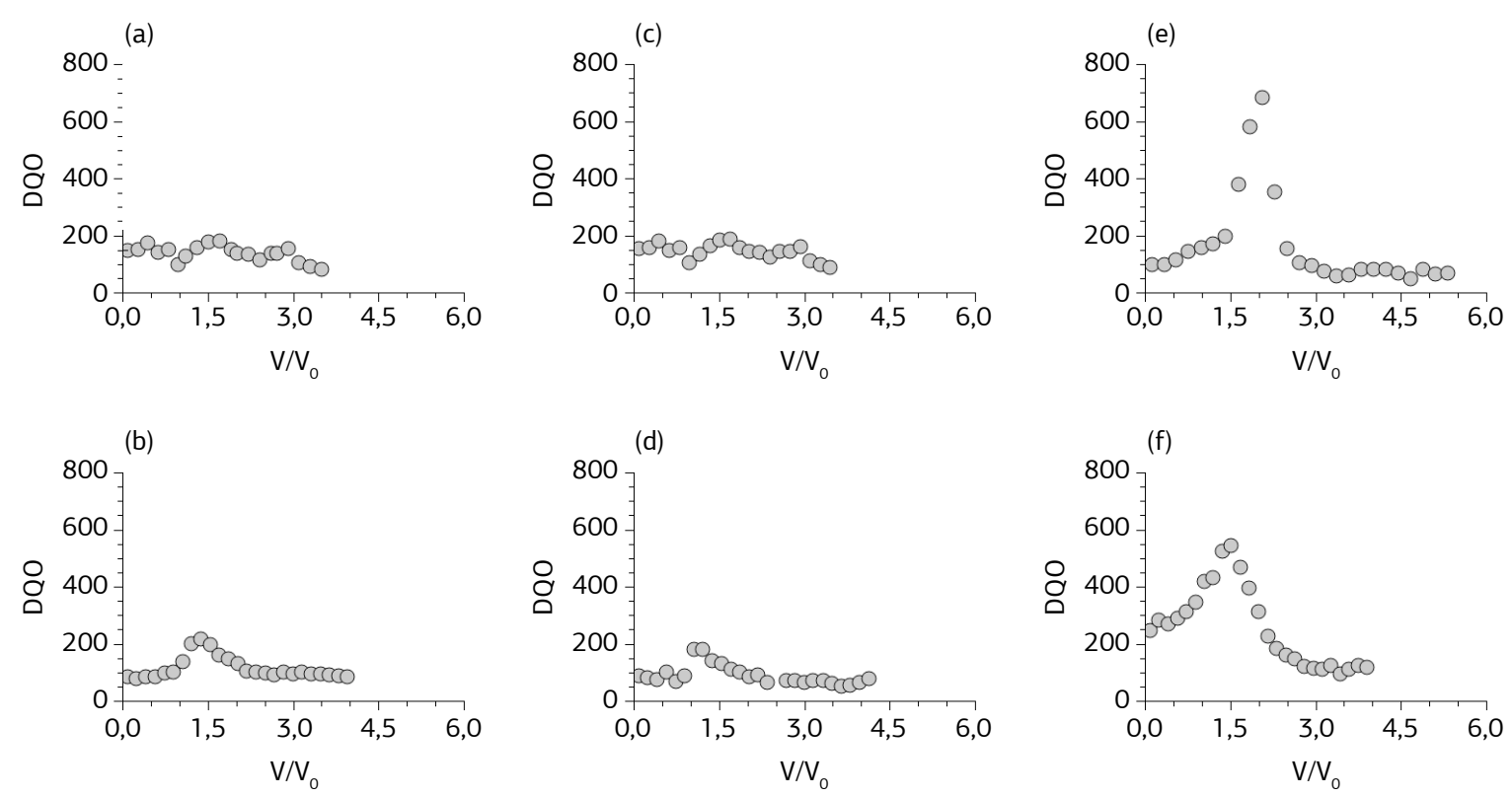

Figura 2. Curvas de transposição obtidas para DQO (em mg O, L-1): (a) LA-B; (b) FOSF; (c) ACID; (d) ACID-FOSF; (e) BASE e (f) BASEFOSF. $\mathrm{V} / \mathrm{V}_{0}$ : volume de poros de pulso+soluçáo deslocadora aplicado (adimensional). Os pontos correspondem à média de duas determinaçóes. 
representando um efeito deletério à microfauna quando acumulado em águas subterrâneas, estando bem acima do limite máximo recomendado para lançamento em corpos de água por SPerling (1996), de $90 \mathrm{mg} \mathrm{O}_{2} \mathrm{~L}^{-1}$. Esses resultados sugerem a necessidade de se iniciar estudos no campo da ecotoxicologia desses efluentes antes de seu lançamento no ambiente. Normalmente, como os microrganismos ficam aderidos ao solo e náo na água, esse efeito da percolação pelo solo na DQO do líquido lixiviado não tem sido explorado na literatura, o que valoriza a importância dos resultados aqui obtidos. $\mathrm{Se}$, por um lado, a falta de trabalhos na literatura nesse contexto torna esse assunto um campo a ser explorado, por outro lado, a comparação com dados de literatura fica prejudicada.

Neste trabalho, a técnica de PCR-DGGE foi utilizada para uma análise independente do cultivo da comunidade microbiana em estudo, tendo como limite de detecçáo, grupos que representam ao menos $1 \%$ da comunidade bacteriana total. Neste estudo, os perfis de DGGE revelaram perfis similares de bandas (Figura 3) nas amostras de solo sem tratamento (controle) e com aplicação de tratamentos.

No gel de DGGE, observam-se os amplicons obtidos que foram separados de acordo com seu comportamento desnaturante. A maioria das bandas parece ser oriunda de amplificação inespecífica (regiâo central do gel), o que se deve principalmente à limitada quantidade de DNA obtida das amostras. Nos solos amostrados, existe menor quantidade de bactérias em relação àquela encontrada em solos oriundos diretamente do campo. Há que se considerar que foram utilizadas amostras do horizonte B (normalmente com menor quantidade de matéria orgânica e de atividade orgânica em relação ao horizonte $\mathrm{A}$ ), que foram armazenadas secas antes da sua utilização.

Assim, a quantidade de DNA extraída para uma boa análise de DGGE ficou comprometida, limitando as inferências sobre a alteração da comunidade bacteriana causada pelos tratamentos.

Algumas hipóteses podem ser elaboradas para explicar a pequena quantidade de DNA extraída das células bacterianas nos solos das colunas. Entre essas hipóteses, é possível supor que os processos que governam a adsorção e movimentação de $\mathrm{N}$ nessas colunas de amostras de solo deformado sejam de natureza não biológica. Ou seja, a movimentação e adsorção seriam principalmente governadas por processos químicos (e físicos), corroborando com o enfoque químico (e físico) dado à questấo nesse trabalho. Outra explicação, que não exclui a anterior, é que os elevados valores de DQO encontrados no líquido que percolou pela coluna estariam sendo prejudiciais aos microrganimos existentes no solo. Se isso realmente estiver acontecendo, os resultados aqui observados servem de alerta para a importância de incluir a DQO em estudos de lixiviação de elementos pelo solo, principalmente nas

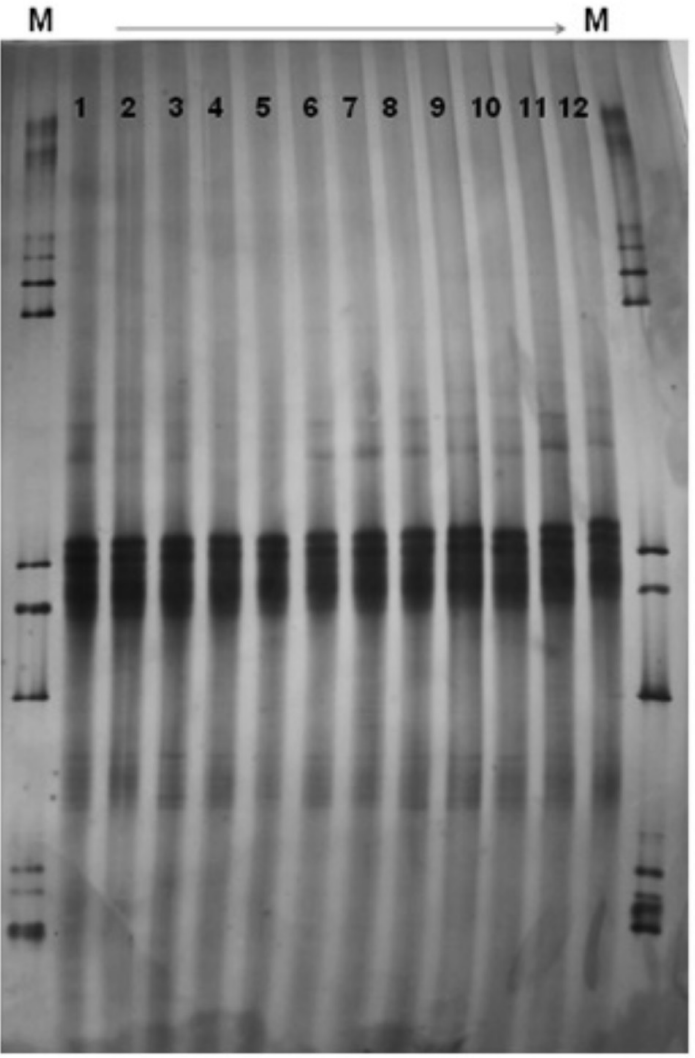

Figura 3. Análise de PCR-DGGE em amostras de solo controle e submetidos a diferentes tratamentos, onde os marcadores de corrida são representados por $\mathrm{M}$. Amostras 1 e 2: LA-B-controle; 3 e 4: ACID; 5 e 6: ACID+FOSF; 9 e 10: FOSF; 11 e 12: BASE+FOSF.

situações em que a participação microbiana possa influenciar nas reaçóes envolvidas, quer seja de adsorçáa, movimentação ou degradação.

Finalmente, cabe lembrar que, a princípio, deve-se evitar a extrapolação direta dos resultados de colunas de lixiviação para condiçôes de campo, pois são situaçóes distintas em relação aos pressupostos teóricos e experimentais envolvidos. Tais extrapolações exigem prudência.

\section{CONCLUSÃO}

Há correlação significativa entre as curvas de transposição de $\mathrm{N}$ obtidas experimentalmente e as simuladas pelo aplicativo STANMOD para a maioria das colunas. A única exceçáo ocorre para a coluna ACID FOSF. Além disso, não há correlação entre CEL e as variáveis de ajuste do modelo FR, $\mathrm{D}$ e $\mu$.

A adição de fosfato (FOSF) favorece a movimentação do nitrogênio, na medida em que diminui o FR e o $\mu$ e aumenta o $\mathrm{D}$ em relaçáo ao observado na coluna sem adição de corretivos e fertilizantes (LA-B). Já a adição de carbonatos e/ou fosfatos (BASE, BASE/FOSF e FOSF) resulta nos maiores valores máximos de demanda química de oxigênio $\left(\mathrm{DQO}_{\text {MÁX }}\right)$. 
A pequena quantidade de DNA extraída das células bacterianas nos solos sugere que, possivelmente, os processos que governam a adsorção e movimentação de $\mathrm{N}$ sejam de natureza não biológica e/ou que os microrganismos existentes no solo estejam sendo prejudicados pela elevada DQO do líquido percolado.

\section{REFERÊNCIAS}

ALCÂNTARA, M.A.K.; CAMARGO, O.A. Fator de retardamento e coeficiente de dispersão-difusão para o crômio (III) em solos muito intemperizados, influenciados pelo $\mathrm{pH}$, textura e matéria orgânica. Revista Brasileira de Ciência do Solo, v.25, p.209-216, 2001.

ALCÂNTARA, M.A.K.; CAMARGO, O.A. Chromium movement in columns of two highly weathered soils. Communications in Soil Science and Plant Analysis, v.35, p.599-613, 2004.

ALCÂNTARA, M.A.K.; CAMARGO, O.A. Adsorção de nitrato em solos com cargas variáveis. Pesquisa Agropecuária Brasileira, v.48, p.369-376, 2005.

ALCÂNTARA , M.A.K.; CAMARGO, O.A. Movimentação de nitrato em horizonte superficial e subsuperficial de Latossolo e Nitossolo com cargas variáveis. Pesquisa Agropecuária Brasileira, v.45, p.81-88, 2010a.

ALCÂNTARA , M.A.K.; CAMARGO, O.A. Manipulação de carga e movimento de nitrato em horizontes B de um Latossolo Vermelho acriférrico. Pesquisa Agropecuária Brasileira, v.45, p.204-212, 2010 b.

ALCÂNTARA, M.A.K.; AQUINO NETO, V., CAMARGO, O.A., CANTARELLA, H. Mineralizaçáo do nitrogênio em solos tratados com lodos de curtume. Pesquisa Agropecuária Brasileira, v.42, p. 547-555, 2007.

ANDREOTE, F.D.; AZEVEDO, J.L.; ARAÚJO, W.L. Assessing the diversity of bacterial communities associated with plants. Brazilian Journal of Microbiology, v.40, p.417-432, 2009.

BARIZON, R.R.M.; LAVORENTI, A.; REGITANO, J.B.; PRATA, F; TORNISIELO, V.L. Simulação do transporte e da sorção de imazaquim em colunas de solo. Revista Brasileira de Ciência do Solo, v.30, p.615-623, 2006.

BRASIL. Ministério Do Meio Ambiente. Conselho Nacional de Meio Ambiente. Resolução no 357 de 17 de março de 2005: Dispóe sobre a classificaçáo dos corpos de água e diretrizes ambientais para o seu enquadramento, bem como estabelece as condições e padrôes de lançamento de efluentes, e dá outras providências. Brasília: CONAMA, 2005.

CAMARGO, O.A.; MONIZ, A.C.; JORGE, J.A.; VALADARES, J.M.A.S. Métodos de analise química, mineralógica e física de solos do Instituto Agronômico de Campinas. Campinas: Instituto Agronômico, 2009. 77p. (Boletim técnico, 106, Edição revista e atualizada)

CETESB - COMPANHIA DE TECNOLOGIA DE SANEAMENTO AMBIENTAL (CETESB). Relatório de qualidade das águas interiores do estado de São Paulo. São Paulo: CETESB, 2005. v.1, 307p.
DONN, M.J.; MENZIES, N.W. Simulated rainwater effects on anion exchange capacity and nitrate retention in Ferrosols. Australian Journal of Soil Research, v.43, p.33-42, 2005a.

DONN, M.J.; MENZIES, N.W. The effect of ionic strength and anion competition on the development of nitrate accumulations in variable charge soils. Australian Journal of Soil Research, v.43, p.43-50, 2005b.

EMBRAPA - EMPRESA BRASILEIRA DE PESQUISA AGROPECUÁRIA. Sistema brasileiro de classificação de solos. Brasília: EMBRAPA Produção de informação. Rio de Janeiro: EMBRAPA, Solos, 2006. 306p.

JELLALI, S.; DIAMANTOPOULOS, E.; KALLALI, H.; BENNACEUR, S.; ANANE, M.; JEDIDI, N. Dynamic sorption of ammonium by sandy soil in fixed bed columns: evaluation of equilibrium and non-equilibrium transport process. Journal of Environmental Management, v.91, p.897-905, 2010.

NIELSEN, D.R.; Van GENUCHTEN, M.T.; BIGGAR, J.W. Water flow and solute transport process in the unsaturated zone. Water Resources Research, v.22, p.89-108, 1986.

QAFOKU, N.P.; SUMNER, M.E. Retention and transport of calcium nitrate in variable charge subsoils. Soil Science, v.166, p.297-307, 2001.

RAIJ, B. van; ANDRADE, J.C.; CANTARELLA, H.; QUAGGIO, J.A. Análise química para avaliação da fertilidade de solos tropicais. RAIJ, B. van, ANDRADE, J.C.; CANTARELLA, H. QUAGGIO, J.A. (Ed.). Campinas: Instituto Agronômico, 2001. 285p.

SIMUNEK, J.; GENUCHTEN, M.Th. van; SEJNA, M. Development and Applications of the HYDRUS and STANMOD Software Packages and Related Codes. Vadose Zone Journal, v.7, p.587-600, 2008.

SPERLING, M. von. Introdução à qualidade das águas e ao tratamento de esgotos. Belo Horizonte: DESA/UFMG., 1996. v.1, p.246.

TORIDE, N.; LEIJ, F. J.; GENUCHTEN, M. Th. van. The CXTFIT code for estimating transport parameters from laboratory or field tracer experiments, Version 2.0. Riverside, CA: U.S. Salinity Laboratory, USDA, ARS, 1995. (Research Report n. ${ }^{\circ} 137$ )

ZHANG, H.X.; SONG, Sh.P.; TAO, Z.Y. Effect of flow rate on the sorption breakthrough behaviors of uranium (VI), phosphate and fulvic acids onto a silica column. Journal of Radioanalytical and Nuclear Chemistry, v.281, p.505-511, 2009.

ZHAO, B.; ZHANG, J.; GONG, J.; ZHANG, H.; ZHANG, G. Glyphosate mobility in soils by phosphate application: laboratory column experiments. Geoderma, v.149, p.290-297, 2009.

ZHENG, C.; BENNETT, G.D. Applied contaminant transport modeling. 2.ed. New York: John Wiley, 2004. 621p. 